This item was submitted to Loughborough's Research Repository by the author.

Items in Figshare are protected by copyright, with all rights reserved, unless otherwise indicated.

\title{
A computer integrated unified modelling approach to responsive manufacturing
}

PLEASE CITE THE PUBLISHED VERSION

http://dx.doi.org/10.1504/IJISE.2010.031962

PUBLISHER

(C) Inderscience

VERSION

AM (Accepted Manuscript)

LICENCE

CC BY-NC-ND 4.0

\section{REPOSITORY RECORD}

Masood, Tariq, Richard H. Weston, and Aysin Rahimifard. 2019. "A Computer Integrated Unified Modelling Approach to Responsive Manufacturing”. figshare. https://hdl.handle.net/2134/8659. 
This item was submitted to Loughborough's Institutional Repository (https://dspace.lboro.ac.uk/) by the author and is made available under the following Creative Commons Licence conditions.

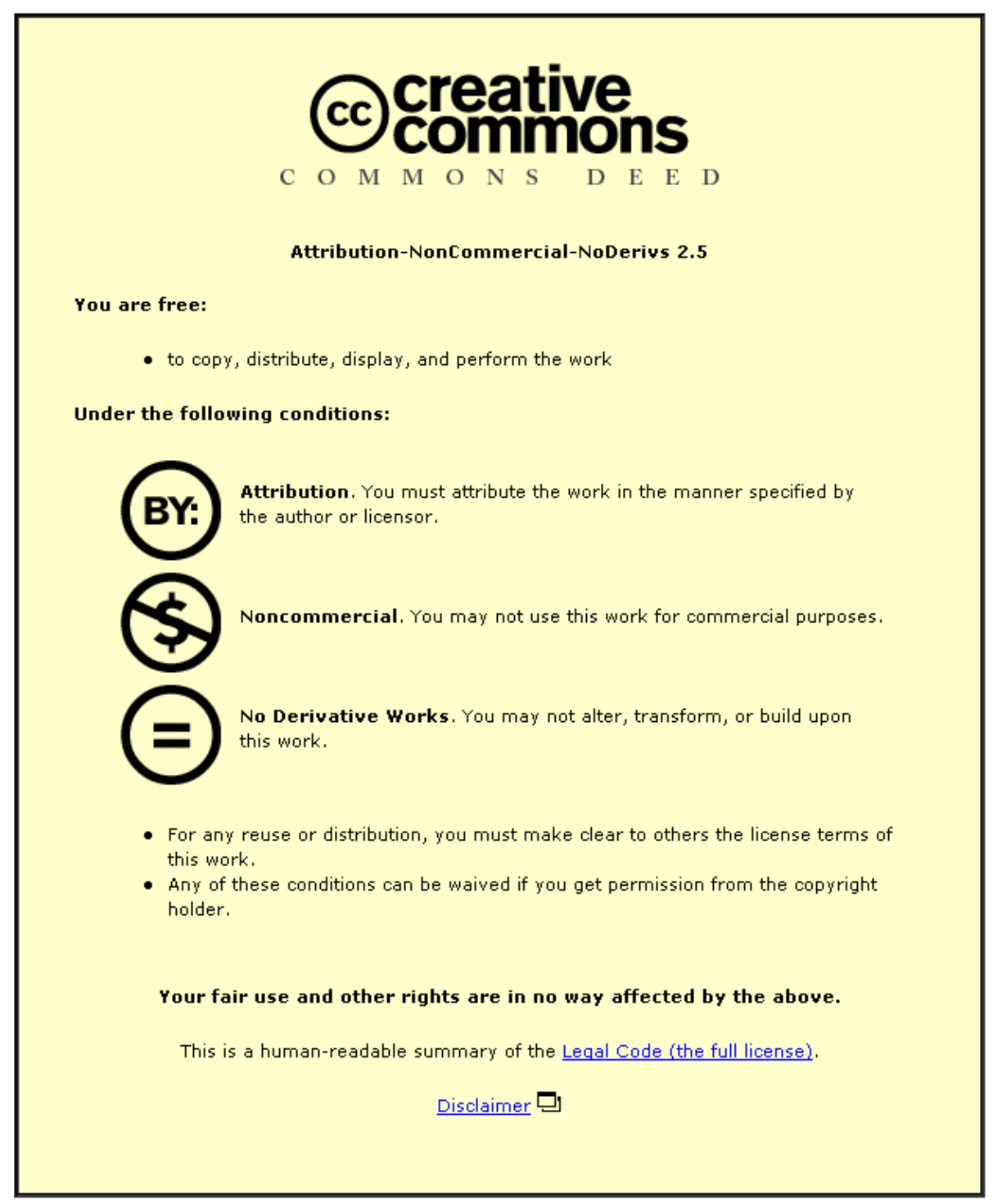

For the full text of this licence, please go to: http://creativecommons.org/licenses/by-nc-nd/2.5/ 


\title{
A computer integrated unified modelling approach to responsive manufacturing
}

\section{Tariq Masood* and Richard Weston}

Manufacturing System Integration (MSI) Research Institute, Loughborough University, Loughborough, Leicestershire LE11 3TU, UK

and

Centre of Excellence in Customised Assembly (CECA), Loughborough University, Loughborough, Leicestershire LE11 3TU, UK

Fax: +44 1509227502

E-mail: T.Masood@lboro.ac.uk;

E-mail: R.H.Weston@lboro.ac.uk

*Corresponding author

\section{Aysin Rahimifard}

Manufacturing System Integration (MSI) Research Institute, Loughborough University, Loughborough, Leicestershire LE11 3TU, UK

Fax: +44 1509227502

E-mail: A.Rahimifard@lboro.ac.uk

\begin{abstract}
Computer modelling approaches have significant potential to enable decision-making about various aspects of responsive manufacturing. In order to understand the system prior to the selection of any responsiveness strategy, multiple process segments of organisations need to be modelled. The article presents a novel systematic approach for creating coherent sets of unified enterprise, simulation and other supporting models that collectively facilitate responsiveness. In this approach, enterprise models are used to explicitly define relatively enduring relationships between (i) production planning and control (PPC) processes, that implement a particular strategy and (ii) process-oriented elements of production systems, that are work loaded by the PPC processes. Coherent simulation models, can in part be derived from the enterprise models, so that they computer execute production system behaviours. In this way, time-based performance outcomes can be simulated; so that the impacts of alternative PPC strategies on the planning and controlling historical or forecasted patterns of workflow, through (current and possible future) production system models, can be analysed. The article describes the unified modelling approach conceived and its application in a furniture industry case study small and medium enterprise (SME).
\end{abstract}

Keywords: computer integrated modelling; enterprise modelling; ODC; organisation design and change; PPC; production planning and control; responsive manufacturing; simulation modelling; unified modelling.

Copyright (C) 2010 Inderscience Enterprises Ltd. 
Reference to this paper should be made as follows: Masood, T., Weston, R. and Rahimifard, A. (2010) 'A computer integrated unified modelling approach to responsive manufacturing', Int. J. Industrial and Systems Engineering, Vol. 5, No. 3, pp.287-312.

Biographical notes: Tariq Masood is currently a $\mathrm{PhD}$ student in the MSI Research Institute while working with UK's Centre of Excellence in Customised Assembly at Loughborough University. He received his BSc in Mechanical Engineering and MSc in Industrial and Manufacturing Engineering. Before joining MSI Research Institute and then CECA, he was working as an Academician and Industry Consultant including research and development engineering companies in Pakistan. He has published numerous technical papers in professional academic journals and conferences. He has also been an active referee and acted as session chair for several conferences. His current research interests include: digital engineering/manufacturing, computer integrated manufacturing systems, reconfigurable manufacturing systems, enterprise design and change, enterprise modelling, simulation modelling, workflow modelling, production planning and control, CAD/CAM, CNC machines, informatics and artificial intelligence. He is also an IRCA certified (ISO 9000) quality management system lead auditor.

Richard Weston $(\mathrm{PhD}, \mathrm{BSc})$ is a Founder Member and Head of the MSI Research Institute and Founder Member and Academic Director of the UK's Centre of Excellence in Customised Assembly and Professor of Flexible Automation at Loughborough University. He has successfully supervised over $60 \mathrm{PhD}$ studies in areas of enterprise modelling, enterprise integration, software systems engineering, human systems modelling, methods-based engineering and flexible automation and has authored around 350 publications in journals, conference proceedings and books. He has been Principle Investigator for over 50 UK research council grants and industry funded contracts and Technical consultant for various manufacturing businesses on systems integration and enterprise modelling techniques. Previously, he has been vice chair of the IFIP Working Group 5.12 on Architectures for Enterprise Integration; member of the EC-Framework VI review panel for Networked Businesses and member of various national (EPSRC, DTI, LINK and BS); and member of the editorial boards of five international journals. He is a Consultant Professor at Harbin Institute of Technology in China.

Aysin Rahimifard is currently a Research Associate in the Manufacturing System Integration (MSI) Research Institute at Loughborough University, Loughborough, UK. After receiving her BSc in Industrial Engineering at Bilkent University in Turkey, she worked for the Turkish Science and Technology Council (TUBITAK) as a Research and Development Engineer where she participated in European Eureka Projects aimed at developing IT tools to support manufacturing management and in national e-government projects. She obtained a $\mathrm{PhD}$ in 2004 at Loughborough University in the area of developing production planning and information support tools for Environmentally Conscious Manufacturing. She then joined MSI where she works with a number of large and small UK manufacturing companies on government funded research and development projects which primarily involve organisational design and change. Her current research interests are in production management, agile manufacturing, enterprise design and change, production planning and simulation modelling. 


\section{Introduction}

Because of growing demand for customised products it is crucial that many manufacturing enterprise (ME) to adopt responsive manufacturing methodologies. Effective use of a production planning and control (PPC) system in any given ME can significantly enhance organisations responsiveness. Hence, it is crucial to adopt and maintain an efficient PPC system in order to satisfying dynamic customer demands and expectations in highly competitive manufacturing environments (Stevenson, Hendry and Kingsman, 2005).

This article describes how a unified modelling approach based on an ISO standard enterprise modelling reference architecture and methodology (namely computer integrated manufacturing open system architecture (CIMOSA)) has been used to: create a 'process map' of a case study manufacturing organisation; decompose that map into segments of that organisation's reality that can usefully be modelled; structure the design, development and deployment of simulation models, based on the complementary use of PPC strategies; facilitate the interpretation of simulated behaviours of segmented models of reality, with respect to causal and temporal impacts that individually modelled organisational segments would have on overall business behaviours of that organisation.

The article is arranged as follows. Section 2 presents a review of the relevant enterprise and simulation modelling work. In Section 3, relevant PPC strategies are discussed, while Section 4 details the proposed unified modelling approach. In Sections 5 and 6, a description of a case study application of the modelling approach is given. Section 7 contains the conclusions of the article along with future scope of work.

\section{Choice of systematic modelling approach}

This article describes a new approach to modelling responsive manufacturing systems with emphasis on selecting and applying suitable PPC strategies. The purpose of this section is to provide a basis for understanding founding ideas that constitute the 'unified modelling' approach conceived during this research.

\subsection{Enterprise modelling}

Enterprise modelling has been defined as 'an art of externalising enterprise knowledge which adds value to the enterprise or needs to be shared. It consists of making models of the structure, behaviour and organisation of the enterprise' (Vernadat, 2002). The main motivations for enterprise modelling are (Vernadat, 2002):

1 managing system complexity by understanding how the enterprise works

2 capitalisation of enterprise knowledge and know-how

3 enterprise engineering and continuous process improvement

4 better management of all types of processes

5 enterprise integration itself.

All things to be integrated and coordinated need to be modelled to some extent. Enterprise integration cannot be achieved without enterprise modelling. Enterprise modelling is clearly a pre-requisite to enterprise integration while enterprise integration is 
first of all a matter of business process coordination and cooperative decision-making (Petrie, 1992; Ladet and Vernadat, 1995; Norrie, 1995; Kosanke, 1997; Vernadat, 2002). Business processes to be integrated or computer-controlled need to be formalised in some way as well as the objects they use, handle or process, information accessed or generated, resources required to execute them, and responsibilities and authorities required for their control. Vernadat $(1996,2002)$ summarises that enterprise modelling aims to provide:

1 a better understanding of the enterprise structure and operations

2 support for enterprise engineering of existing or new parts of the enterprise

3 a model which can be used to control and monitor enterprise operations.

Enterprise modelling also supports process management activities. Effective monitoring and control of processes ensures that models remain current and conversely that processes follow the prescribed model(s). An improved vision of the process being managed implies a better and more appropriate assigning of measures of performance. Avoiding the use of arbitrary measures and implementing more specific metrics yields a realistic view of performance. A similar argument can be formed for the enterprise management function, although it must be acknowledged that models tend towards a higher aggregation as they proceed up the functional hierarchy (Vernadat, 1996). Enterprise modelling stems from the need to understand the causal implications of pursuing certain actions over others without affecting real-time processes. By creating a model, whether it is dynamic or static, complexity can be minimised. The Oxford Dictionary of English definition of a model supports this view. It states that a model is a "simplified description, especially a mathematical one, of a system or process, to assist calculations and predictions". Any type of model, whether it is mathematical, graphical or physical, provides an abstraction of reality for the purposes of creating a comprehendible and consensual depiction of a given real world scenario. Enterprises are systems that can be analysed and modelled using systems theory (ISO14258, 1998). An enterprise model is defined as: "A consistent set of special purpose and complementary models describing the various facets of an enterprise to satisfy some purpose of some business users" (Vernadat, 1996).

It is important to acknowledge the fact that enterprises are becoming evermore complex and are now analogous to natural systems (Ladet and Vernadat, 1995). The models of different functions or entities link up to give entirety to the whole system model. In reality, constituent models exist that collectively represent the required aspects of the enterprise, to the level of abstraction that is required (Vernadat, 1996). Thus any given enterprise modelling does not provide a turnkey solution for users wishing to represent an enterprise rather it provides a knowledge base about relatively enduring aspects of an enterprise which can be used for a variety of organisation design and change (ODC) purposes. Whilst Vernadat's definition is rather generalised, the following elaborates on the purpose of business users and intentions sought through modelling an enterprise: "A representation of what an enterprise intends to accomplish, how it operates and possibly how it is organised, which is used to improve the effectiveness and efficiency of the enterprise" (ISO14258, 1998). Vernadat's definition relates the purpose of modelling to the end user of the model. The ISO stance is that models have a more discrete purpose than serving the enterprise in pursuit of improvements. The ISO definition gives an indication of the development of a future (TO-BE) model that addresses the inefficiencies highlighted through modelling the current (AS-IS) situation. 
Anomalies aside, the consensus view is that enterprise modellings enable a systematic approach to understanding a given enterprise and that this understanding will facilitate improvements to the way in which an enterprise performs (Vernadat, 1996; Lim, Juster and de Pennington, 1997; Szegheo, 2000).

\subsection{Integration frameworks in support of enterprise modelling}

There are a number of different modelling and integration frameworks available to use for enterprise integration. Major frameworks include:

1 integrated enterprise modelling (IEM) approach

\section{CIMOSA}

3 generalised enterprise reference architecture and methodology (GERAM)

4 integrated computer aided manufacturing definition (IDEF) suite methods

5 architecture of integrated information systems (ARIS)

6 Purdue enterprise reference architecture (PERA).

Figure 1 The computer integrated manufacturing open system architecture modelling framework (see online version for colours)

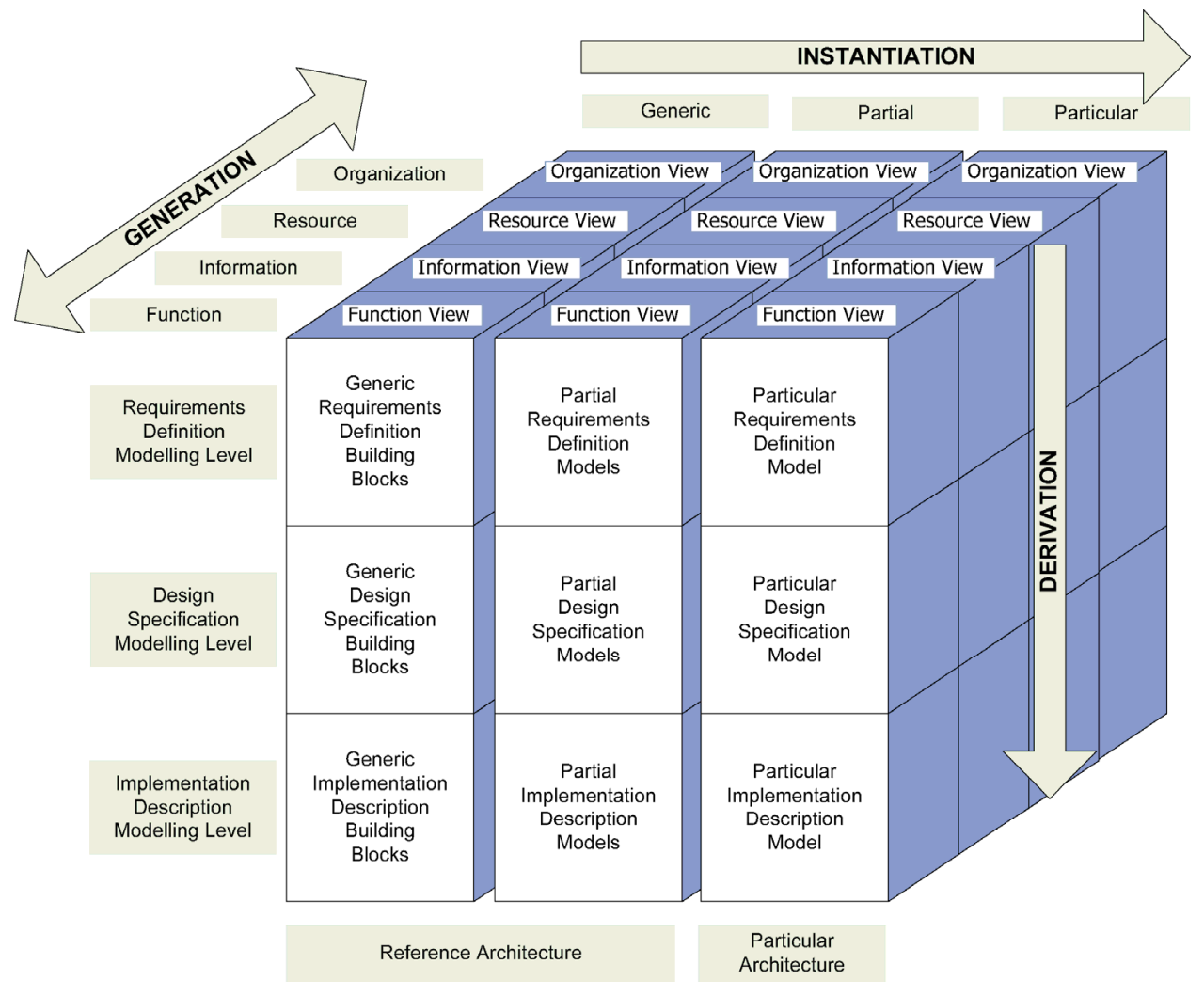


CIMOSA is an ISO enterprise modelling technique that is widely accepted and has produced significant industrial benefits (Bernus and Nemes, 1996; Kosanke and Zelm, 1999; Monfared, 2000; Chatha, 2004; Weston et al., 2006; Masood, 2007). Therefore, CIMOSA is selected as a basis for the proposed unified modelling approach to responsive manufacturing systems. CIMOSA allows the AS-IS situation within an enterprise to be modelled as well as any suggested TO-BE configurations or scenarios. A bottom-up approach can be taken when considering change to existing implementations and/or a top-down approach when planning implementations. The CIMOSA modelling framework is shown in Figure 1.

CIMOSA provides benefits to the business enterprise in a number of areas according to Bernus and Nemes (1996), these benefits are:

1 Improving enterprise operational flexibility and efficiency by reengineering and simplification of business processes.

2 Supporting the management of change via the evaluation of alternatives through the simulation of operations.

3 Improving operation flexibility and efficiency and reducing operational costs through better business management (people, processes, resources and information).

4 Reducing lead times through the sharing and reuse of relevant information, modelling building blocks and system components.

\subsection{State of the art approaches to combining the use of enterprise modelling and simulation modelling}

An illustrative method was developed by Monfared (2000) to provide graphical representation for the CIMOSA modelling architecture. Monfared's approach proposes four graphical modelling templates, namely; context diagram, structure diagram, interaction diagram and activity diagram. The context diagram defines CIMOSA (and non-CIMOSA) domains to be modelled and their relationships. The structure diagram identifies and decomposes domain processes into business processes and enterprise activities. The interaction diagram shows interactions between dependant domain processes and defines the inputs and outputs of domain processes in terms of the flow of material, information and control. The activity diagram represents flow of processes, procedural rules and conditions related to the functionality of each process in respect with the flow of control, information and time. Collectively, these diagrams support the decomposition of domains into enterprise activities.

Building upon Monfared's approach, Chatha, Weston and Monfared (2003), Chatha (2004) developed the enriched multi-process modelling (E-MPM) method by enriching static models in order to close the static-simulation model gap. Monfared's approach provides a rich static representation of sequences of activities and allows decomposition of domains in accordance with CIMOSA principles. It does not however support any real-time interactivity with the process being modelled or allow information to be encoded in an executable format. An appreciation of time is given in the activity diagram. The elaborated behaviour of activity threads over time, i.e. dynamics are not supported or represented in Monfared's approach. This led to the development of the E-MPM method. The aim of this approach was to extend Monfared's diagramming technique to encompass simulation aspects. 
An initial work on transforming process segments coded by enterprise modellings into equivalent simulation modellings was presented by Rahimifard and Weston (2007). They observed technical, practical, business and social constraints on the widespread application of enterprise modelling. They found primarily the technical factors that constrain on the use of current enterprise modelling approaches and arise mainly because contemporary public domain enterprise modelling techniques provide limited capabilities to encode and computer execute temporal aspects of process networks. They also found that it was not practical to encode into a unified enterprise model all relevant (to enterprise organisation and its environment) causal and temporal entities and factors that can influence current and possible future ME behaviours. Rahimifard and Weston (2007) also found that it could only prove feasible to deploy a unitary simulation model to replicate and predict holistic ME behaviours at a very high level of abstraction. Hence for the foreseeable future it was presumed by Rahimifard and Weston (2007) that enterprise models would continue to major on representing relatively static properties of process networks which lend them to graphical representation, and that some primary constraints would exist on the use of such models.

However since these works, combined uses of enterprise modelling and simulation modelling have been utilised to support various aspects of ODC decision-making. But the present authors believe that further research is needed to investigate the interplay between enterprise models and simulation models. It has been observed that enterprise modellings and their embellishments usefully encode a restricted but coherent set of relatively enduring entities, entity relationships and properties which can be used to facilitate the design and building of coherent simulation modellings (Rahimifard and Weston, 2007; Weston et al., 2007). Enterprise modellings offer significant potential as a repository of reusable model structures, modelled entities and specific ME knowledge and data. These can be reused when creating simulation modellings. In principle, multiple and coherent sets of simulation modellings can be created at required levels of abstraction and used to replicate, analyse and predict activity, process segment and whole process network behaviours. The key is the reuse of model structures as opposed to reuse of specific enterprise data. Simulation model builders will still need to capture dynamic properties of enterprises and conduct experiments that test the validity of models before they are used to support organisation and design decision-making. The same process needs to be followed while using the unified modelling approach for a PPC system being representative of responsiveness in a manufacturing system.

\section{Production planning and control in responsive manufacturing organisations}

The present authors hold the view that adopting and maintaining an efficient PPC system is crucial in many MEs that face increasingly dynamic customer demands. It has also been noted that adopting a PPC strategy should cover: management of customer demand, scheduling and sequencing of jobs, capacity planning, and meeting material requirements. Due to increasingly dynamic customer demands and expectations in the present highly competitive manufacturing environment, it is crucial to adopt and maintain an efficient PPC system (Stevenson, Hendry and Kingsman, 2005). These strategic PPC elements help a business to: minimise throughput time and lead time; reduce work in progress (WIP); keep inventory costs at a minimum; improve responsiveness to change in demand (resulting in changes in product and process some times); improve delivery date 
adherence. These are important objectives, and choosing the right PPC approach and system is hence a crucial strategic decision (Stevenson, Hendry and Kingsman, 2005). It follows that these PPC elements can in principle facilitate improved ME responsiveness whilst possibly deploying unchanged production and assembly system processes and resources. But if the demand changes significantly to realise such benefits the PPC system itself must be changed appropriately to realise both local and distributed utilisation of production resources and materials (Lima, Sousa and Martins, 2006).

It has been observed that modern manufacturing systems must be: flexible/agile, reactive, integrated and cost efficient (Ladet and Vernadat, 1995). It also follows that ME personnel must have (individual and collective) in-depth understandings about specific processes and resource systems and that these processes must be flexible enough to change whenever the need arises (Masood, Rahimifard and Weston, 2007). Such requirements place further emphasis on the PPC System, which must be dynamically adaptable to both local and distributed utilisation of production resources and materials (Lima, Sousa and Martins, 2006). Thus the design and re-design of such systems requires the adoption of systematic approaches which deploy various types of system model to understand current and possible future behaviours and to form ongoing decision-making as environmental and organisational changes occur. PPC in support of responsive manufacturing inherently requires organisations to have 'change capability' characteristics; suitable distribution of production resources and some degree of autonomy of production resources.

The production of finished items or components to meet an existing order is called make-to-order (MTO). In a MTO company, products are made to the customer's specification, and are often processed in small batches. Different PPC approaches applied to MTO companies are referred to in the literature: as aggregate planning; master production planning; production planning and scheduling, push, pull, constant work in progress (CONWIP) and postponement approaches (Tabe, Murumatsu and Tanaka, 1980; Spearman, Woodruff and Hopp, 1990; Berkeley, 1992; Zapfel, 1996; Bonvik, Couch and Gershwin, 1997). These approaches can be based on the use of 'tools' like material requirement planning and just in time (Ohno, 1988; Monden, 1993; Stevenson, Hendry and Kingsman, 2005). Determining the right choice of PPC strategy is complex because of the increasing number of alternative variants of these approaches. MEs that need to cope with uncertainties in demand commonly require responsive manufacturing systems which can readily be reconfigured to maintain alignment with changing production plans. Choosing and implementing a PPC strategy and system may prove costly to most of MTO companies. Hence MEs need a systematic approach which helps them choose a suitable way of achieving PPC. Thus, the present authors conclude that the design and redesign of PPC systems requires an adoption of a systematic approach which enables enterprise engineering teams to understand current and possible future behaviours and support ongoing decision-making as environmental and organisational changes occur.

\section{Computer integrated unified modelling approach in support of responsive manufacturing}

The forging discussion shows that modelling approaches have a significant role to play in enabling decision-making, including support for PPC selection, in responsive manufacturing organisations. Analysis of business processes aided by enterprise 
modelling and integration can reduce risks and increase chances of implementing successful business processes. It also enables organisations to capitalise knowledge so that it can react by changing operations in an effective, efficient and responsive manner. Systematic decomposition and analysis of complex systems is possible with the aid of supporting architectures and by using complementary modelling techniques which can include enterprise modelling, causal loop modelling (CLM), simulation modelling and workflow modelling (Weston et al., 2006). The models of ME processes, resource systems and workflows created need themselves to be reconfigurable and interoperable in order to synchronise between virtual and real elements of processes and systems that need to interoperate within dynamic (often uncertain) environments (Weston et al., 2007). In principle, by achieving a unification of different modelling approaches new opportunities will arise to make the models live and responsive to upcoming but 'yet to be determined' rapid changes (Weston et al., 2007).

CIMOSA provides a coherent set of modelling constructs to explicitly represent the processes, resource systems, information flows and organisational structures of MEs as depicted in Figure 1. Along the 'derivation' dimension it provides multi-perspective modelling constructs that enable decomposition of the enterprise so that understandings gained about how processes are decomposed into process segments and the high levels of complexity can be handled and elemental activities. In this way, understandings about relatively enduring structural aspects of processes can be gained at various levels of abstraction. Thereby both: 'big picture understandings' can be developed that cross organisational boundaries; and in-depth process analysis can be enabled by 'drilling into' the model in great detail. The 'generation' dimension is concerned with the life cycle of the ME and its processes, resources, information flows and organisational structures. Here definitive separation is made between 'models of requirements' (generally expressed as process models that can be treated as a backbone model and attributed with other modelled entities) and 'models of conceptual solutions', 'detailed models of specific solutions' and 'implementation descriptions' used to document implemented systems capable of meeting defined requirements. In general, the solutions will be configurations of active resource components (including people, automated machines and IT systems). The third CIMOSA cube dimension 'instantiation' is concerned with the extent to which 'models' and 'implemented solutions' are general or specific. This third dimension is of prime concern later in this article. The basic idea is that enterprise models might describe MEs or parts of them in general or may describe some industry sector or common sectoral aspects of many MEs or may simply describe one particular ME or even just one particular part of one ME. Here in principle enterprise modellers and other enterprise engineers and decision-makers can particularise a generic model through a partially generic modelling stage to an ME specific one. Alternatively, generalisation of specific or semi-generic models can lead to models and solutions that can be generally applied. In this scheme of things therefore an enterprise resource planning (ERP) package is a semi-generic solution technology which can be made specific by inputting specific product data related to a specific ME.

Enterprise modelling (including CIMOSA) is designed to represent and communicate primarily structural aspects of ME. CIMOSA modelling constructs are not designed to be computer executed to simulate ME state change. Hence where simulation experiments are needed to predict future behaviours of ME processes configured in different ways, and when using alternative resource systems, it is necessary to complement the use of enterprise modelling with simulation modelling technologies. 
Figure 2 The 'generic unified modelling' approach in support of responsive manufacturing (see online version for colours)

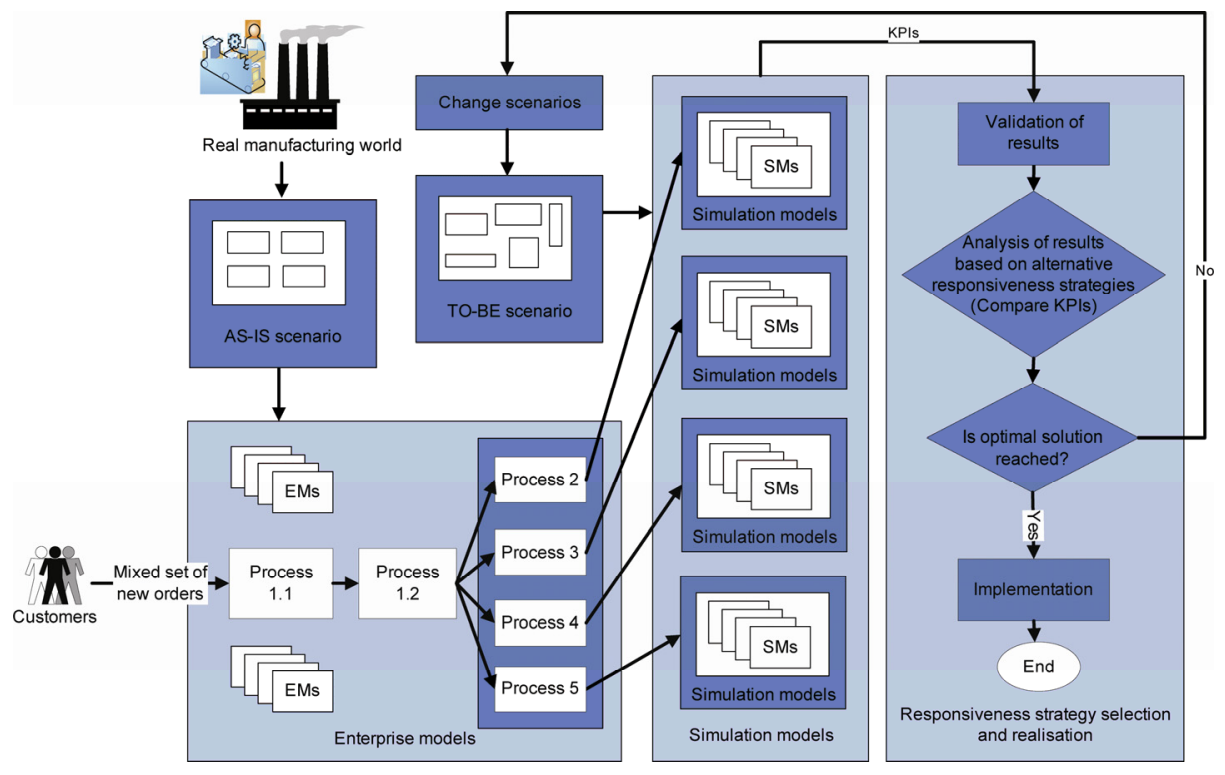

This article describes the basis of such a systematic approach to creating coherent sets of computer integrated unified models that can interoperate to replicate and predict changing organisational behaviours. The computer integrated unified modelling approach in support of responsive manufacturing, shown in Figure 2, can be positioned at the generic level of CIMOSA modelling. This approach will be referred to as 'generic unified modelling' and involves the following main steps:

Step 1. Development of enterprise models; to represent a specific ME and its product realising processes.

Step 2. Development of simulation models of relevant processes where it is necessary to consider and encode

1 The nature of the work that flows through production systems, where these systems comprise both 'process elements' and 'resource system elements'.

2 Best ways of configuring the production system elements, such that required 'values' can be added to those workflows. Also during simulation model development certain key performance indicators (KPIs) need to be identified and selected to enable comparison to be drawn between the performances of alternative strategies and production system configurations.

Step 3. The AS-IS enterprise and simulation models need validation before starting TO-BE model generation. Also, upon reaching a near optimal responsiveness solution, the results require validation, then presentation to relevant funders and managers; before final selection of strategy and production system configurations are made.

Step 4. Analysis of results; based on ME deployment of current (AS-IS) and possible future (TO-BE) responsiveness strategies; where KPIs are used to predict and compare production system behaviours under alternative strategies. 
Step 5. Implementation of the finalised responsiveness solution; within the host ME.

Very commonly PPC systems are used to improve the responsiveness of MEs. It follows that the selection of an effective PPC system can play a pivotal role in ensuring responsiveness of the whole manufacturing system. In this research, therefore, any semi-generic scenario of PPC strategy selection and realisation is considered to correspond to a 'domain unified modelling' approach; which is a more specific case of Figure 2. This article will explain how the 'generic unified modelling' approach, described by Figure 2, was used to support PPC strategy selection in a MTO furniture producing SME which will be referred to as $\mathrm{ABC}$. When so doing however PPC strategy selection for $\mathrm{ABC}$ was focussed primarily on one process segment concerned with cabinet assembly. As illustrated in Figure 3, this was considered to be a 'particular application of the unified modelling' approach.

Figure 3 illustrates a 'particular application of the unified modelling' approach beyond the stages of data capture where enterprise models are prepared. Simulation models are run using alternative PPC strategies when inputting the same set of new customer order data into (AS-IS) and possible (TO-BE) configurations of production systems (for machining, assembly, spraying and finishing in the $\mathrm{ABC}$ case). Before running the simulations, certain KPIs are chosen to enable comparison and choice to be made between different combinations of PPC strategy and production systems configuration. As soon as a near optimal solution is reached the modelling and decision-making process is stopped, otherwise it is carried on to find additional combinations of (TO-BE) PPC strategies and production system configurations.

Figure 3 'Particular application of the unified modelling' approach in support of responsive manufacturing: PPC strategy selection and realisation for cabinet assembly in ABC (see online version for colours)

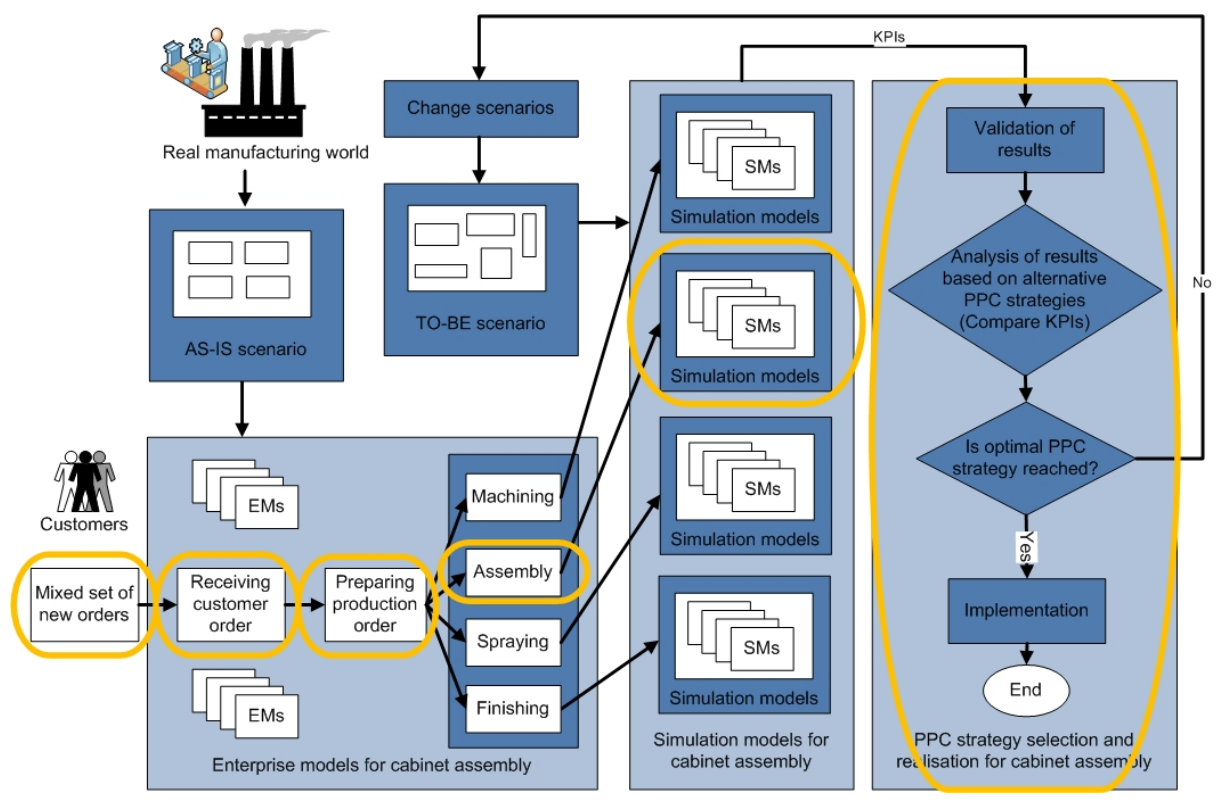




\section{Case study background}

The case study company (referred to as $\mathrm{ABC}$ ) is a furniture manufacturing SME with 50 employees. It operates primarily within the UK but has European suppliers of raw material. It manufactures over 300 different furniture products from pine wood; including a range of tables, cabinets, beds, wardrobes and other furniture items that are designed for both house hold and business users. The application of a number of alternative PPC strategies has been investigated in order to improve responsiveness of $\mathrm{ABC}$ to rapidly changing market demands. Capturing and reusing enterprise and simulation models of $A B C$ 's business processes (human and technical), resource systems and dynamic patterns of multi-product workflows have been created.

The main production processes involved in $\mathrm{ABC}$ 's furniture manufacturing are machining, assembly, spraying and finishing. ABC's current production system operates according to a MTO strategy, and is triggered by groupings of customer orders based upon logistical criteria related to customers categorised by UK location. A self owned fleet of lorries are used to deliver customer orders. Production 'runs' are constrained by the capacity of these lorries or by a pre-set maximum order collating time of four weeks (whichever constraint is exceeded first).

According to ABC's current PPC strategy, the company compiles orders received from customers on weekly basis. The production starts with the issuance of a production order (known as 'sales order picking list' in $\mathrm{ABC}$ ) to the assembly shop. The production order is then reviewed by the assembly shop coordinator who generates a 'Machine Shop Production Order' that requests needed parts from ABC's machine shop. The job list of the machine shop is regularly updated and priorities are set in order to maintain smooth running of the assembly shop. The production order is then moved through the assembly shop after receiving parts to be assembled from the machine shop where assembly processes are carried out.

The assembly department of $\mathrm{ABC}$ mainly consists of two sections, namely, cabinet assembly and table assembly sections. Each section has its own work organisation, but appeared to have commonalities in planning and scheduling approach. This section briefly explains related issues for cabinet section which is the focus of this article and the overall assembly production planning system. In cabinet section, there are six main workbenches that are organised into three sub-sections. Some cabinets are being made in two stages in a flow shop fashion, the operators refer to them as first fix and second fix whereas others go through only one stage before moving to next shop, i.e. spray shop. Thus, in this section, out of six workbenches, two are allocated to first fix operations and three are allocated to second fix operations. Remaining one bench is allocated to one stage cabinet products. In addition to six main workbenches, there are two more workbenches that are specialised in making auxiliary cabinet parts and small items, namely, one is for making small items such as nest of tables, mirrors, CD racks and the other is for making auxiliary cabinet parts such as drawers, plinth and H-Frame. Since these two workbenches are working independent of the other sections of the cabinet area in terms of planning and work loading, they remain outside the scope of the simulation study.

The assembly area deploys a 'real-time scheduling' approach where there is no frozen schedule and the question of 'what-to-do next' is attempted every time a job is finished based on the current status of ever changing job list, level of resources and due dates. The (human) resources are almost fully floating across different sections, sometimes even 
across departments. Assembly area has three production supervisors, one being the overall assembly coordinator, the other two being the respective section sub-supervisors for table assembly and cabinet assembly sections. The picking list is received from customer order processing department twice a week by the assembly coordinator. Then, he prepares 'partial picking' lists by highlighting the relevant furniture items for each assembly area and pass it to the workbenches. Every time a workbench finishes a job the next job is picked from the highlighted list according to earliest due date and minimum setup time (MST) sequencing rules. The similar items are grouped together and some items are made in batches to save the setup time if they are in the same delivery run.

It was noted that high variety of more than 300 products contains both less frequent and highly demanded products during certain periods which were unknown. There were no forecasting methods being adopted and product demands were unpredictable. After a number of visits to the company and number of discussions with company management and operators, initial data was collected. Following which enterprise models of the MTO processes of $\mathrm{ABC}$ were created and validated by the company managers.

\section{Case study modelling}

This section describes case study modelling in $\mathrm{ABC}$ which corresponds to a "particular application of the unified modelling approach' and Steps 1-3 as described in Section 4.

\subsection{Step 1: development of enterprise models of $A B C$}

To capture an AS-IS model of the current combination of PPC strategy and production system configurations used by $\mathrm{ABC}$, enterprise models of the company have been developed after several visits to the company. Previous publications of the present authors have described in some detail the way CIMOSA diagrams populated to create the enterprise model of $\mathrm{ABC}$ (Weston et al., 2006; (Masood, 2007). In the study reported here, focus was on improving best practice PPC in the company and when so doing to consider other possible production system configurations which might enhance the profitability of ABC. Figure 4 shows a CIMOSA sub-interaction diagram for plan and control product realisation, which was designated as business process (BP62) of ABC. The plan and control product realisation process (BP62) interacts with processes realised by furniture stores, designated as 'stockists' (i.e. BP61) so that orders are received and acknowledged. It also interacts with processes that maintain internal stock at suitable levels (BP63). Further interaction is with the domain process DP7 (produce and deliver furniture) via the issue of production and delivery schedules, monitoring production and exception handling. The domain processes DP8 (introduce product) and DP9 (analyse market) and the business processes BP65 (developing strategy), BP66 (improving business) and BP64 (control bradgate finances) also have interactions as shown in Figure 4.

The activity diagram of ABC's BP11-1 (receive customer order) is also shown in Figure 4 . The production planner decomposes the orders into local orders by adopting a scheduling strategy which seeks to optimise the use of ABC's fleet of lorries. This requires the imposition of a geographical location constraint which arises because of the need to group orders by common due dates and customer locations. A control sheet is 
maintained with reference to that constraint and a picking list is generated. Figure 4 shows the 'Prepare Production Order' business process BP11-2.

Figure 4 An exemplary set of top level context diagram, sub-interaction diagram and activity diagrams (see online version for colours)

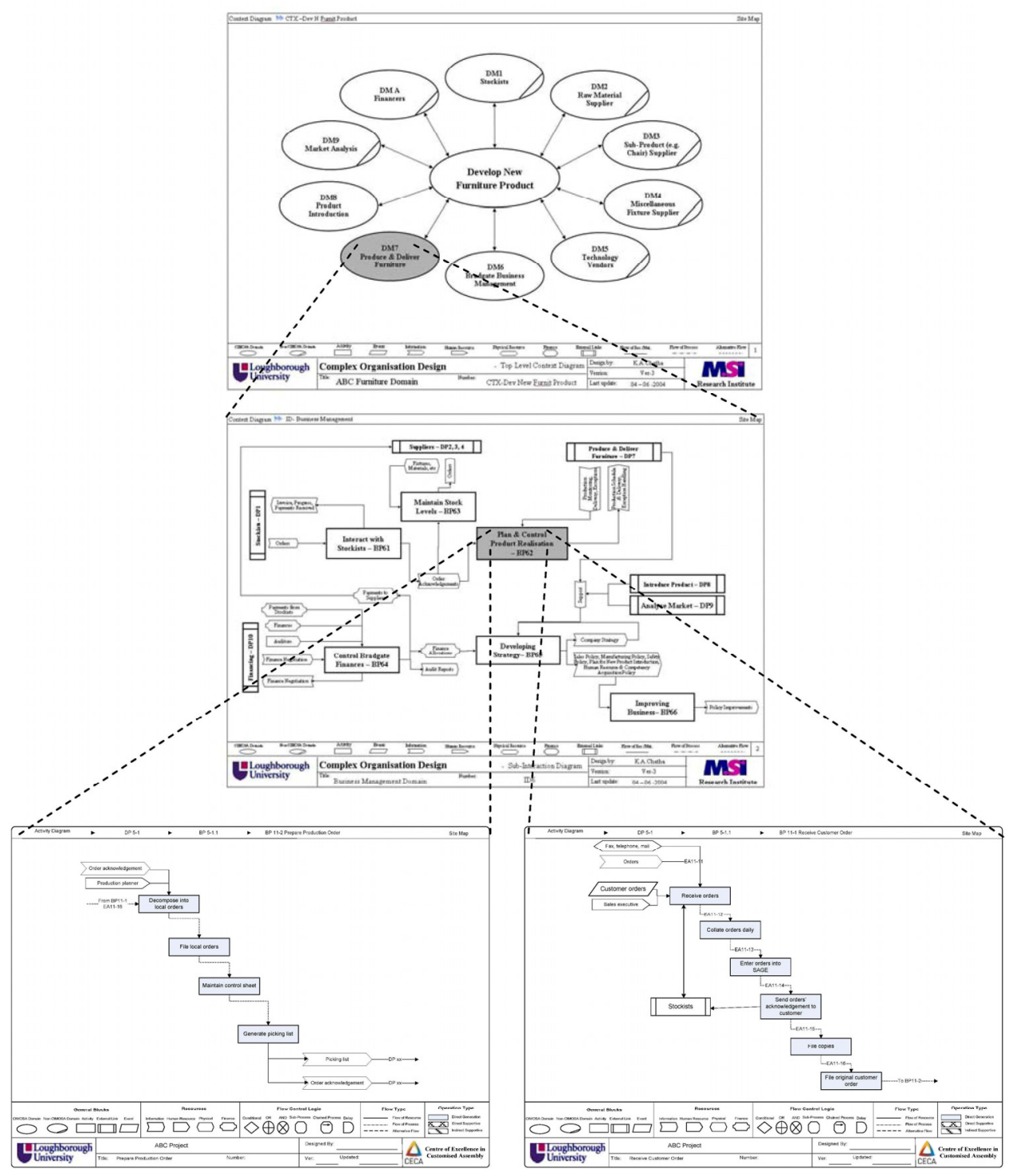


Figure 5 Unified modelling language information model of ABC's production plan (see online version for colours)

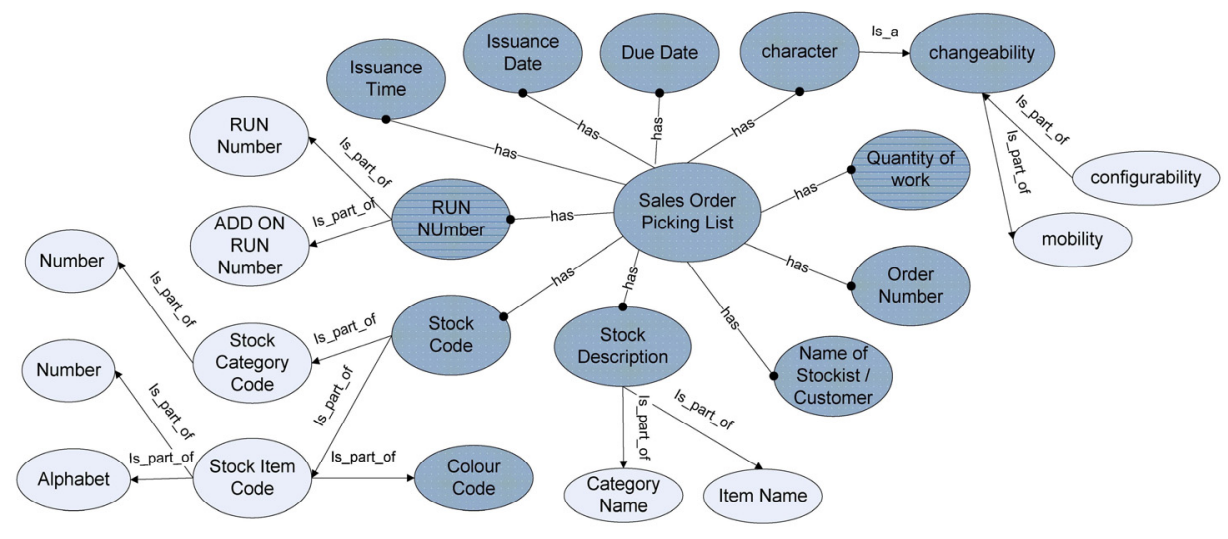

It was observed that the enterprise modelling of $\mathrm{ABC}$ provided an explicit description of relatively enduring relationships between activities carried out during planning and control, and during production and purchasing. It was evident that these relationships define a process-oriented structure that can be recoded using simulation technologies. This idea is developed in sub-section 6.2. The activity relationships made explicit by $A B C$ 's enterprise modelling were also used to create an information model related to the planning and control of ABC's production systems. This information model was developed to explicitly describe PPC decision-making in ABC. Here the unified modelling language was used to encode information entities and their relationships within ABC's production orders (sales order picking lists). The information model created is presented in Figure 5.

Production order defines: 'run number'/'add on run number', (customer) order number, quantity of work, issue date and time, due date, stock category code (which has a numeric value), stock item code (which has an alpha-numeric code) and a colour code. Also it contains a stock description showing a category name and item name and the name of the stockist (customer). This information model aided the authors' understandings about characteristics of $\mathrm{ABC}$ 's current production order system.

\subsection{Step 2: development of simulation models of $A B C$}

A general purpose simulation model of MTO production processes at $\mathrm{ABC}$ was built on the basis of foregoing analysis. Here a proprietary discrete event simulator (namely Simul8) has been chosen as opposed to a system dynamics tool. This was mainly because, firstly, the timings of the events are of the prime importance to the purpose of the modelling exercise, i.e. inter-arrival time, lead time, queuing time, etc. and, secondly; the identity of specific products and/or product types with associated attributes needed to be maintained for benchmarking purposes. The simulation model developed is general purpose in that it facilitates experimentation (with respect to needed process variables identified during CLM), enabling impact analysis of changes to scheduling and work organisation policies. A set of simulation modelling experiments were designed and 
carried out so as to test effects of PPC policy change on 'lead times', 'inventory levels', 'bottlenecks', 'resource utilisation', 'value generation' and 'process costs'.

The AS-IS simulation model developed to bench mark the AS-IS situation of cabinet assembly production at $\mathrm{ABC}$ has been shown in Figure 6. In this simulation model, no cabinet product grouping is used. The cabinet assembly section consists of three sub-sections. The sub-sections 1 and 2 deal with product groups Cab1-Cab8. The sub-section 1 processes at the first instance named as 1 st fix while the sub-section 2 processes after sub-section 1 finishes work named as 2 nd fix. The sub-section 1 has two cabinet fixers called cabinet 1st fixer1 and cabinet 1st fixer2. The sub-section 2 has three cabinet fixers named as cabinet 2nd fixer1, cabinet 2nd fixer2 and cabinet 2nd fixer3 as shown in the AS-IS simulation model. The product groups Cab9-Cab11 are processed by sub-section 3 independently which has only one resource named as single stage cabinet maker.

It is conceived for TO-BE scenarios that the cabinet assembly orders are routed through a PPC section. The TO-BE conceptual model incorporates the MTS/ATO hybrid manufacturing system. It has been assumed in TO-BE simulation models that the products are grouped on the basis of their processes and process times. The TO-BE simulation models have been run with the representative real customer order data for six months based upon the cabinet groups already conceived. Since the cabinet groups 9-11 use a dedicated resource for the production, therefore these groups have been treated separately in the simulation models and related results. Figure 7 illustrates the conceptual base model of the TO-BE cabinet assembly systems along with points of foci:

Figure 6 AS-IS simulation model of ABC cabinet assembly production (see online version for colours)

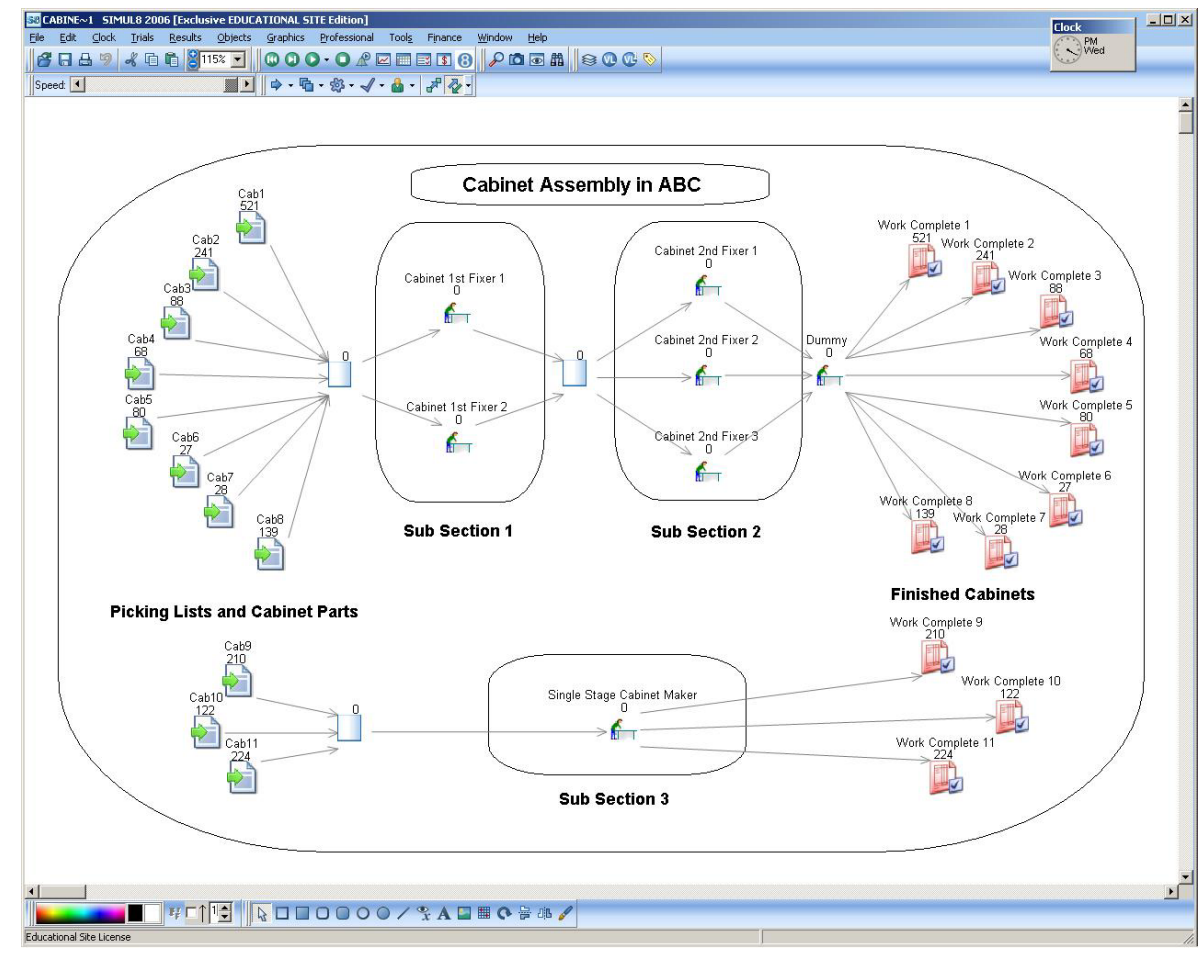


Figure 7 Conceptual base model of the TO-BE cabinet assembly systems (see online version for colours)

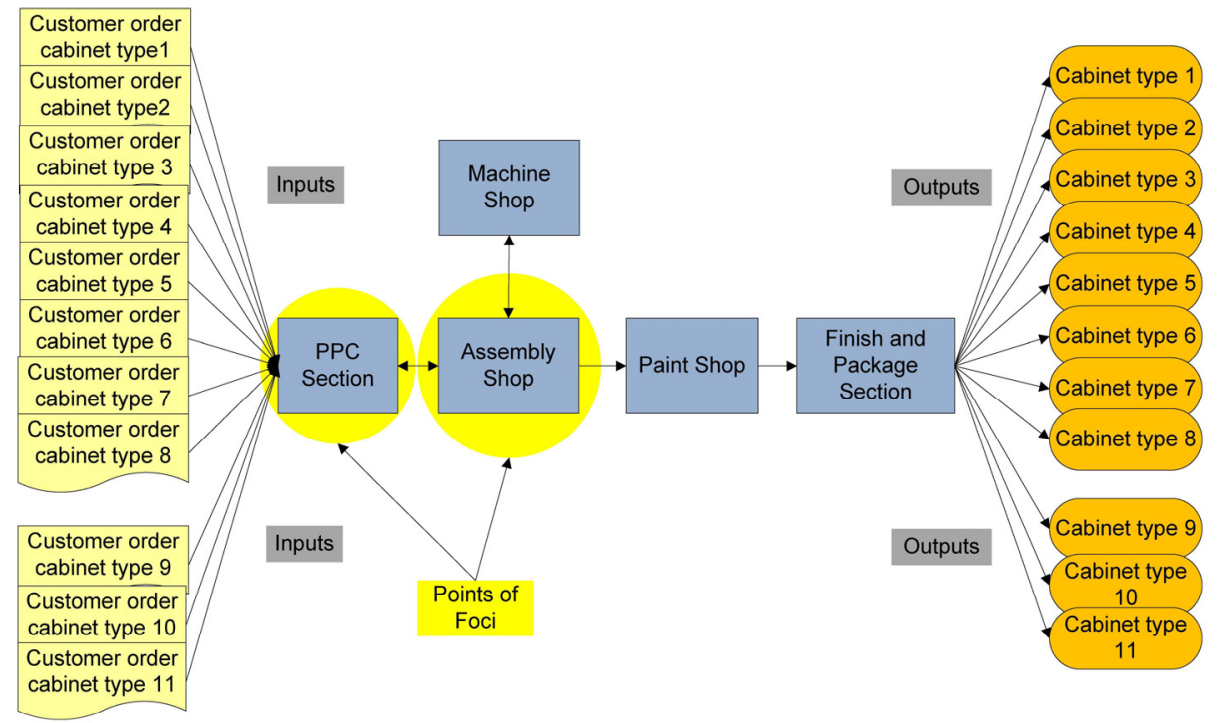

Figure 8 Order behaviour of grouped cabinet batches in ABC over 6-months period (see online version for colours)

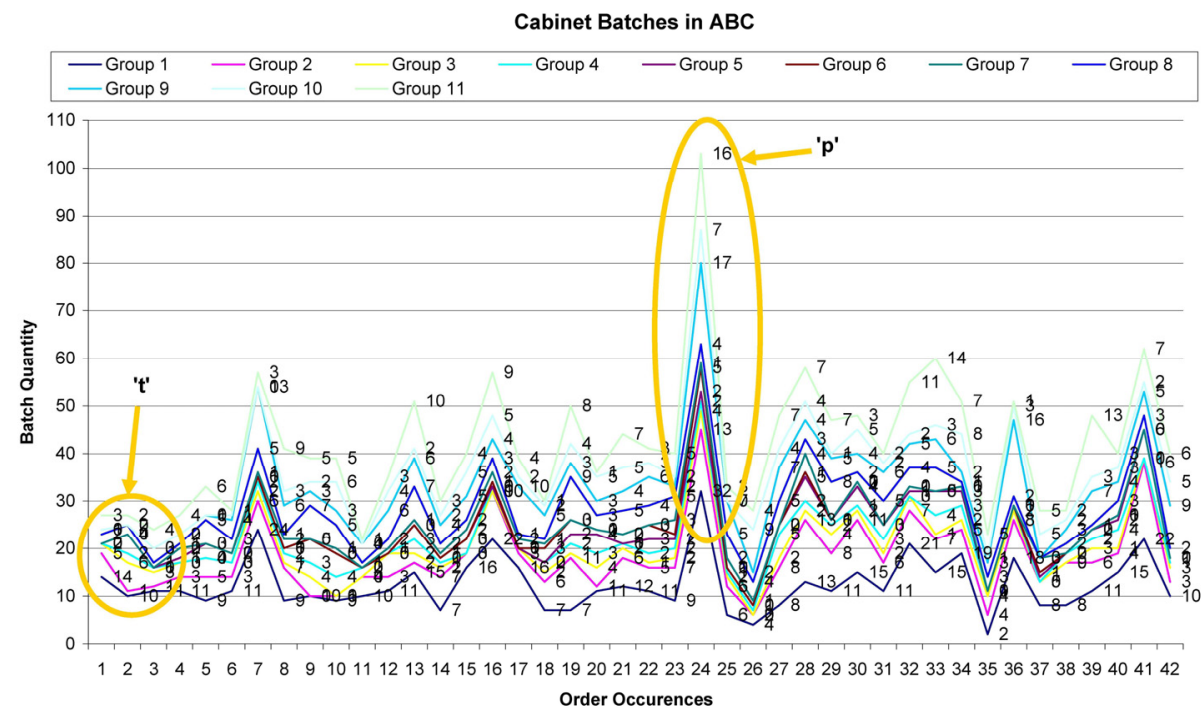


Figure 9 Order behaviour of inter-arrival times of grouped cabinet batches in $\mathrm{ABC}$ over 6-months period (see online version for colours)

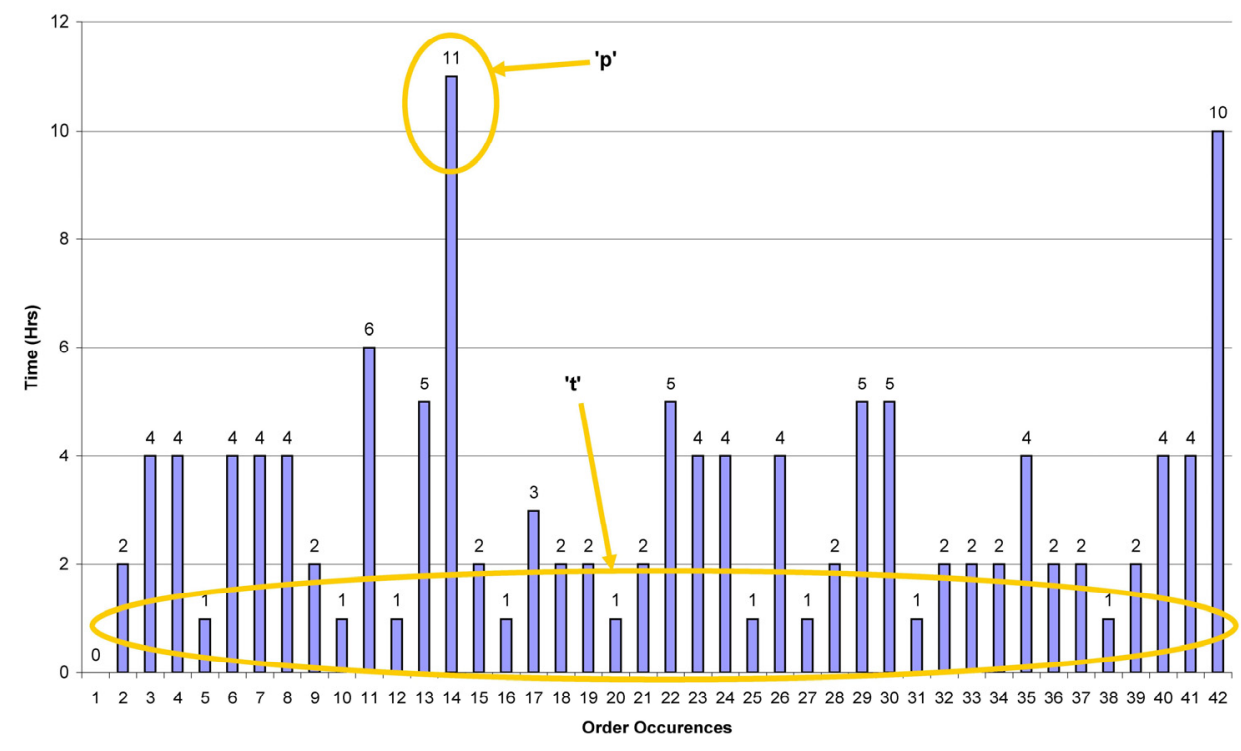

After consultation with the management executives and the operators of the company, the 11 groups of cabinet products referred to earlier were conceived. These groups are based mainly upon the commonality of their processes, process sequences, process times and resources. Figure 8 shows real customer order data for batches of cabinets grouped in ABC. The same set of order data has been used for TO-BE scenario testing with simulation model-based experimentation. The 'peaks' and 'troughs' of the batch quantities for this 6-months period may be found in the figure as ' $p$ ' and ' $t$ '.

The data on inter-arrival times of the customer orders is important in understanding the order behaviour. Figure 9 shows real customer order data for inter-arrival times of grouped cabinet products in $\mathrm{ABC}$. The same set of order data has been used for TO-BE scenarios. The 'peaks' and 'troughs' of the inter-arrival times for this 6-months period may be found in the figure as ' $p$ ' and ' $t$ '. In the following sub-sections, stepwise approach that is outlined previously in Section 4, will be applied on ABC case study to explore improvement opportunities for PPC responsiveness.

\subsection{Step 3: validation of (model) results}

It is important to validate the static and simulation models up to an acceptable level of accuracy. The performance of the model needs to be compared with the operation of the real system or the performance of the designed TO-BE system to build confidence in the results. It is important to note that the model may only be 'valid for the purpose'. In reality, it may not be possible to validate fully a model of a real system (Robinson, 1997; Sargent, 2005; Monfared et al., 2008). The validation method adopted here generally follows the method suggested by Robinson (1997) (i.e. validation of static model, data, codes and black box approaches).

The CIMOSA-based static models of the $\mathrm{ABC}$ production system were created and then converted to the simulation models. Having identified a suitable grouping of $\mathrm{ABC}$ 
product types, that share similar processing routes, processing operations and operation times, these product types were fed individually and in different product type mixes into an AS-IS model of ABC production system. In general terms, the Simul8 models of AS-IS ABC production system behaved in a similar fashion to that observed in the actual production system. Therefore, it was deemed that the model could be used as the basis of 'what if' decision-making.

\subsection{Step 4: selection of key performance indicators, analysis of results and discussion}

There are a number of potential production policies and configurations that can be changed within the virtual environment. These parametric changes to the initial model will generate 'TO-BE' scenarios where potential benefits can be predicted and measured through KPIs. The potential production policies identified as being of major interest to $\mathrm{ABC}$ are as follows:

1 Removal of logistical constraint - in TO-BE scenarios, the logistical constraints have been removed in order to get optimal solution to the problem.

2 Release of 'production order' or 'picking list' - this represents the frequency with which the work arrives at the start of the raw materials process, and will have an effect on work rate reproduced by the process and one or more operations. In TO-BE scenarios, the production orders have been released to the production system as they arrive irrespective of the logistical criteria.

3 Hybrid MTS/ATO strategy - a hybrid MTS/ATO strategy has been adopted. The products are grouped on basis of similarity in processes and process times. The grouped products are fed into the TO-BE simulation models to generate final results.

The KPIs identified as being of major interest to $\mathrm{ABC}$ are as follows:

1 Throughput time (lead time) - the throughput time or lead time is one of the most frequently used KPI and has been used in this case as a major comparator.

2 Cost - cost is also a prime KPI on which alternative production policies are decided.

3 Utilisation of resources - the assignment of resources to work within the assembly section can be optimised for process improvements.

4 WIP levels - the WIP levels play an important role in determining the amount of inventories held in a manufacturing business.

Reduction in lead time (and in effect throughput time) is an important KPI in engineering of an efficient and responsive PPC system. The current system was analysed for future implementation of a hybrid make-to-stock (MTS)/assemble-to-order (ATO) system. We consider a hybrid approach here because the customer orders are characterised by order led customisation of products made up from common and/or similar parts and subassemblies. When populated order behaviours are available, the predictability of orders is better achievable using forecasting methods. Such a MTS/ATO system is practicable in environments where standard parts are available to assemble using postponement approach. With product (re)design, it is achievable to make standard parts which are partially driven by a MTS strategy and partly by an ATO strategy. Implementation of a 
hybrid MTS/ATO system needs better product and process (re)design, availability of stock, availability of bill of material data, availability of forecasted orders, commonality of parts (standardisation of parts or modularisation) and better supplier relationships. Provided this kind of support is available, reduction in lead time is achievable which leads to customer satisfaction and then may result in an increased frequency of orders. All above-mentioned factors enhance the chances of success rate of implementation of hybrid MTS/ATO system. Some key impacts of implementation of a hybrid MTS/ATO system in support of engineering an efficient and responsive PPC system in ABC are illustrated by cause and effect diagram shown in Figure 10.

In candidate TO-BE scenarios, the product input, an external environment variable, has been kept frozen to the real 6-months customer order data for cabinet products. The internal environment variables like resources etc. have been changed to get the optimal results. In candidate TO-BE scenarios, a PPC section has been added to the AS-IS simulation model, as also presented in the conceptual model, in order to switch between alternative plan and control production policies. It is assumed that the PPC section has only one resource and takes 30 minutes on average distribution to process an order. An exemplary TO-BE simulation model has been shown in Figure 11.

The results of the initial model have shown that the 'Single Stage Cabinet Maker 1' was the most occupied resource in 'sub-section 3'. The addition of alternative resources generated alternative TO-BE scenarios and results were recorded. Alternative production scheduling policies were also incorporated in the simulation models to generate optimal results. PPC section model properties and Routing In and Routing Out options have been shown in Figure 12.

Figure 10 Causal effect: implementation of hybrid make-to-stock/assemble-to-order system in support of engineering production planning and control system in $\mathrm{ABC}$ (see online version for colours)

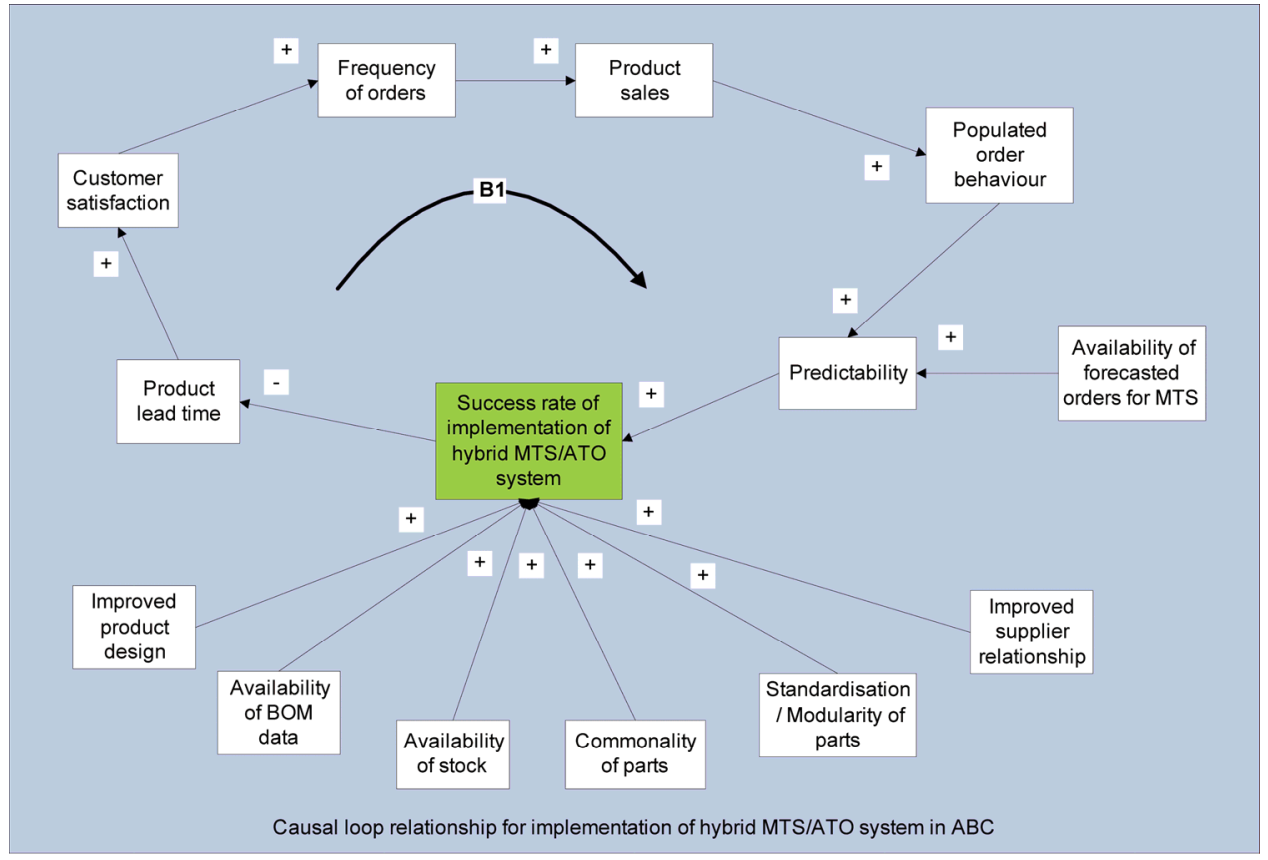


Figure 11 An exemplary TO-BE simulation model of ABC cabinet assembly production planning and control strategy (see online version for colours)

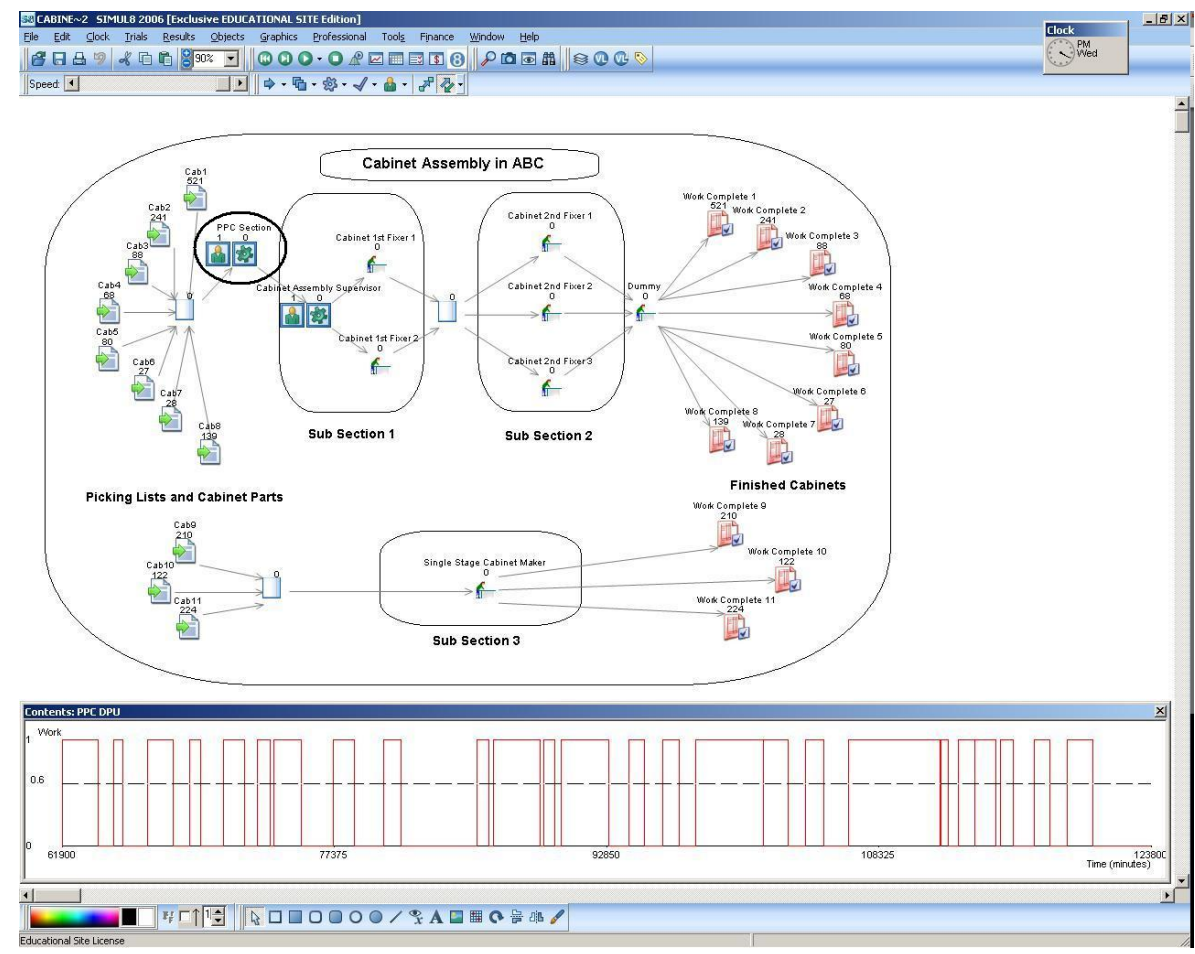

Figure 12 An exemplary production planning and control section model properties and routing in and routing out options (see online version for colours)
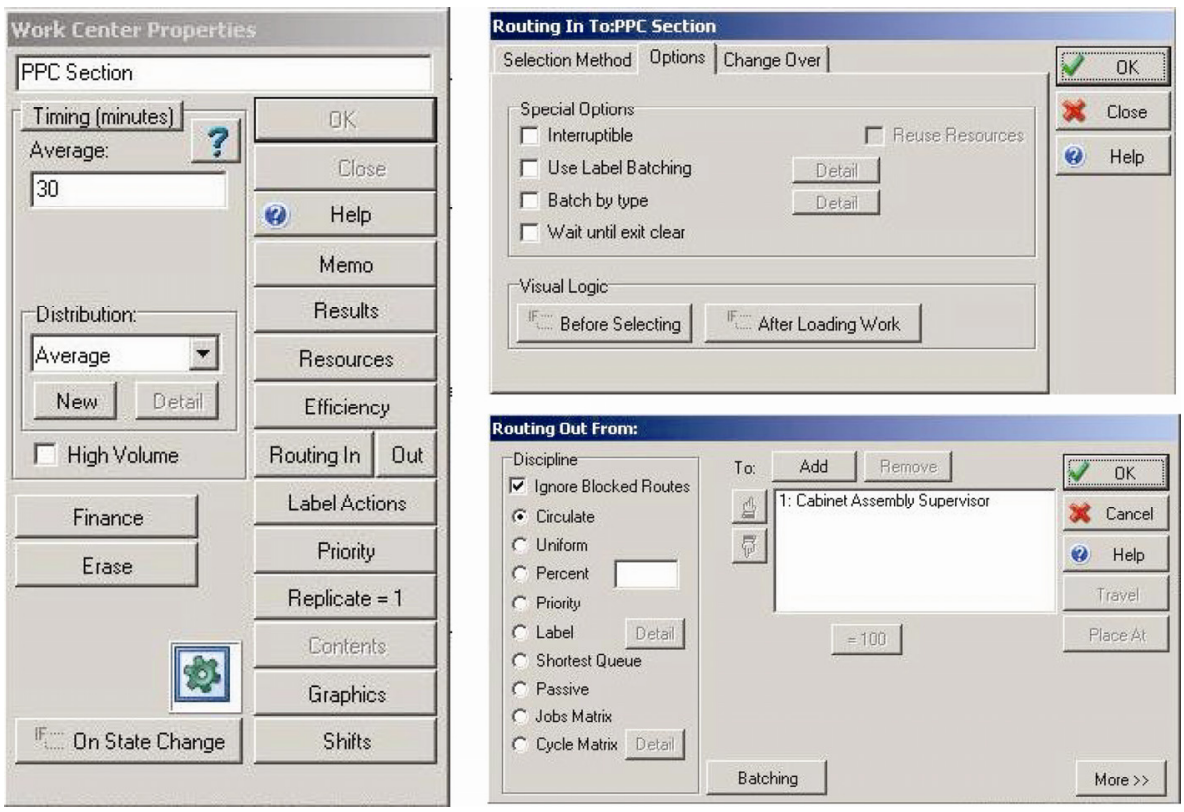
The results have been collected after running the simulation models for 61,900 minutes (approximately 6-months on the basis of 5-days a week, 8-hours a day and 60-minutes an hour) after warming up for the same length of time. Figure 13 shows exemplary lead time results for different cabinet product groups in alternative TO-BE responsive PPC scenarios.

The case study has shown how the computer integrated unified modelling approach for responsive manufacturing has benefited the $\mathrm{ABC}$ in better responding to the fast changing customer demands by applying the CIMOSA-based particular level of modelling methodology for PPC strategy selection and realisation. It was noted that the combined use of enterprise modelling and simulation modelling techniques helped to gain an in-depth understanding about $\mathrm{ABC}$ 's current production strategies, their shortcomings and possible ways of achieving improvements. The proposed responsive approach has been applied to the cabinet assembly section of the ABC production system.

There is no aggregate planning method being adopted in $\mathrm{ABC}$ at this stage resulting in non-visibility of the customer order behaviour. The extent of visibility into the future customer orders plays a pivotal role in fast responses to the market demands. The hidden customer order behaviour in $\mathrm{ABC}$ has resulted in slowness to react to the market needs. In order to achieve optimal results, the $\mathrm{ABC}$ needs to develop an up-to-date comprehensive data base for forecasting needs to be catered. The analysts and modellers of the TO-BE systems could better utilise it to peep into the future customer order behaviours by applying right historical data analysis tools.

MTO strategy is presently adopted in ABC production system. A key disadvantage of this strategy is that the majority of production starts after customer order arrival. This results in increased product lead times. On basis of the proposed approach $A B C$ is envisaged to adopt a hybrid MTS/ATO strategy. In the proposed strategy the production of the parts shall initiate on internal production orders based upon forecasted batches and inter-arrival times. Inclusion of the postponement theory at this level shall result in improved lead times hence throughput times.

Figure 13 Exemplary lead time results for cabinet groups in alternative TO-BE scenarios (see online version for colours)

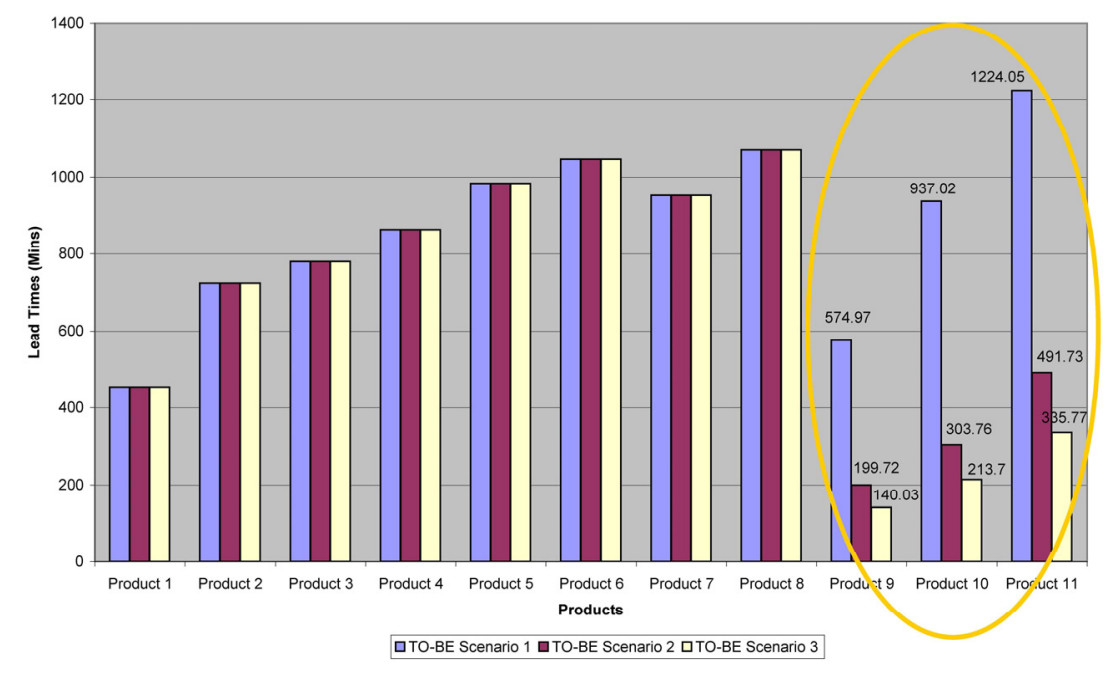


Table 1 Summary of observations and proposed production strategies in ABC

\begin{tabular}{|c|c|c|c|c|}
\hline S. No. & PPC Strategies & Existing ABC Scenario & Observations & Proposed strategies \\
\hline \multirow[t]{2}{*}{1.} & \multirow[t]{2}{*}{ PPC hierarchy } & \multirow[t]{2}{*}{$\begin{array}{l}\text { No aggregate planning } \\
\text { based on forecasting }\end{array}$} & $\begin{array}{l}\text { No visibility of order } \\
\text { behaviour }\end{array}$ & Needs forecasting \\
\hline & & & Slow to react & Historical data analysis \\
\hline \multirow[t]{2}{*}{2.} & \multirow{2}{*}{$\begin{array}{l}\text { Customer order } \\
\text { decoupling }\end{array}$} & \multirow[t]{2}{*}{ Make to order (MTO) } & \multirow{2}{*}{$\begin{array}{l}\text { Majority of production } \\
\text { starts with order } \\
\text { arrival }\end{array}$} & Assemble to order \\
\hline & & & & $\begin{array}{l}\text { Inclusion of } \\
\text { Postponement theory }\end{array}$ \\
\hline \multirow[t]{3}{*}{3.} & \multirow[t]{3}{*}{$\begin{array}{l}\text { Push vs. pull } \\
\text { system }\end{array}$} & \multirow[t]{3}{*}{ Push system } & \multirow[t]{3}{*}{ Longer lead time } & $\begin{array}{l}\text { Pull system where } \\
\text { possible }\end{array}$ \\
\hline & & & & $\begin{array}{l}\text { Production based upon } \\
\text { commonality of parts }\end{array}$ \\
\hline & & & & Parts standardisation \\
\hline 4. & $\begin{array}{l}\text { Production } \\
\text { scheduling }\end{array}$ & $\begin{array}{l}\text { Accumulated order list } \\
\text { due to logistic } \\
\text { constraints }\end{array}$ & $\begin{array}{l}\text { High variety induced } \\
\text { in system bottleneck }\end{array}$ & $\begin{array}{l}\text { Break up of job list by } \\
\text { removing the constraint }\end{array}$ \\
\hline \multirow[t]{3}{*}{5.} & \multirow[t]{3}{*}{$\begin{array}{l}\text { Production } \\
\text { sequencing }\end{array}$} & $\begin{array}{l}\text { First in first out } \\
\text { (FIFO) }\end{array}$ & $\begin{array}{l}\text { Does not reflect global } \\
\text { objectives }\end{array}$ & $\begin{array}{l}\text { Adoption of dynamic } \\
\text { sequencing rules }\end{array}$ \\
\hline & & \multirow[t]{2}{*}{ Minimum setup time } & $\begin{array}{l}\text { Does not take into } \\
\text { account overall lead } \\
\text { time performance } \\
\text { across }\end{array}$ & $\begin{array}{l}\text { Minimum number of } \\
\text { remaining operations }\end{array}$ \\
\hline & & & $\begin{array}{l}\text { Assembly Shop and } \\
\text { ABC }\end{array}$ & $\begin{array}{l}\text { Minimum remaining } \\
\text { process time }\end{array}$ \\
\hline
\end{tabular}

The present $\mathrm{ABC}$ system works on 'push' approach which also results in long lead times again. A proposition for $\mathrm{ABC}$ is to adopt 'pull' approach where possible. The production based upon commonality of parts has been discussed in the superscript sections which adds to the advantages of the proposed approach. The parts standardisation for different groups or sub-groups may be a future work for $\mathrm{ABC}$ in order to achieve full benefits of the 'pull' strategy.

The ABC's approach on generating accumulated customer order list due to the logistical constraints has resulted in highly increased lead times hence throughput times. Due to this approach a high variety of products has been induced in the system bottleneck. It has been discussed in the superscript sections that the proposed TO-BE systems are based upon the break up of production order list by removing the constraint.

The present $\mathrm{ABC}$ working environment is based upon deciding the next work to do on the basis of MST. The present strategy is working fine at local section or sub-section level however results in grave consequences in achieving the global objectives of the business. It does not take into account overall lead time performance across assembly shop and the ABC. The overall lead times are still on the high rise and needs to be tackled in order to sustain the business. The adoption of proposed dynamic sequencing rules may help achieve the global objectives. These strategies based upon dynamic rules may be minimum number of remaining operations on a product or minimum remaining process times so that the $\mathrm{ABC}$ could finish as many products earlier than the normal expected lead times. 
Table 1 summarises key existing $\mathrm{ABC}$ approaches, authors' observations and proposed strategies related to PPC.

\subsection{Step 5: implementation of results}

The experiments proved useful to PPC personnel of $\mathrm{ABC}$ and led to the use of an improved push scheduling policy. The $\mathrm{ABC}$ needs to standardise its components in respect of product (re)design so that the components may be manufactured on forecasted demands and assembled whenever an order is received. There is a scope to further implement the results in real system if possible. There is also a need to devise methods and techniques to update models more frequently in order to reduce the longer time periods involved in the modelling exercises.

\section{Conclusions}

Computer integrated modelling approaches have significant role to play in enabling decision-making in responsive manufacturing organisations. This is true with respect to the engineering of PPC systems in MEs being representative of manufacturing responsiveness. In order to understand customer order dynamics and ME processing abilities and constraints prior to engineering a PPC system, specific ME segments need to be modelled with reference to the overall (ME) business context in which they need to operate. The basis of a systematic approach to creating coherent sets of unified models that facilitate the manufacturing responsiveness is described along with a case study of engineering of PPC system. Enterprise models and simulation models have played a key role to enable PPC decision-making by using the proposed computer integrated unified modelling approach. The design of a PPC system needs to cater for current and future product variance and enable new product introduction. Case study enterprise models are presented which have aided PPC strategy design and resultantly manufacturing responsiveness decision-making in $\mathrm{ABC}$. The article has identified key areas for future research which relate to the use and updating of enterprise and simulation models.

\section{References}

Bernus, P. and Nemes, L. (1996) 'A framework to define a generic enterprise reference architecture and methodology', Journal of Computer Integrated Manufacturing Systems, Vol. 9, No. 3, pp.179-191.

Berkeley, B.J. (1992) 'A review of the kanban production control research literature', Production and Operations Management, Vol. 1, No. 4, pp.393-411.

Bonvik, A.M., Couch, C.E. and Gershwin, S.B. (1997) 'A comparison of production-line control mechanisms', Int. J. Production Research, Vol. 35, No. 3, pp.789-804.

Chatha, K.A. (2004) 'Multi-process modelling approach to complex organisation design', PhD Thesis, Wolfson School of Mechanical and Manufacturing Engineering, Loughborough University, Loughborough, UK.

Chatha, K.A., Weston, R.H., Monfared, R.P. (2003) 'An approach to modelling dependencies linking engineering processes', Paper presented in the Proceedings of the Institute of Mechanical Engineers Part B: Journal of Engineering Manufacture, Vol. 217, pp.669-687. 
ISO14258 (1998) Industrial Automation Systems - Concepts and Rules for Enterprise Models, BSI Standards, UK.

Kosanke, K. (1997) 'Issues in enterprise integration', in K. Kosanke and J.G. Nell (Eds.), 'Enterprise Engineering and Integration: Building International Consensus' Proceedings of ICEIMT '97, International Conference on Enterprise Integration and Modelling Technology, Torino, Italy, 28-30 October 1997, Vol. XVII, 634 p. Springer-Verlag, Softcover, ISBN: 978-3-540-63402-7, Also available at: http://www.springer.com/computer/ information+systems/book/978-3-540-63402-7; http://www.mel.nist.gov/workshop/iceimt97/ ice-fly.htm; http://cimosa.cnt.pl/Events/iceimt97.htm.

Kosanke, K. and Zelm, M. (1999) 'CIMOSA modelling processes', Computers in Industry, Vol. 40. pp.141-153.

Ladet, P. and Vernadat, F.B. (1995) The Dimension of Integrated Systems Engineering. Integrated Manufacturing Systems Engineering. London, UK: Chapman \& Hall.

Lim, S.H., Juster, N. and de Pennington, A. (1997) 'Enterprise modelling and integration: a taxonomy of seven key aspects', Computers in Industry, Vol. 34. pp.339-359.

Lima, R.M., Sousa, R.M. and Martins, P.J. (2006) 'Distributed production planning and control agent-based system', Int. J. Production Research, Vol. 44. pp.3693-3709.

Masood, T. (2007) 'A model-driven approach to engineering production planning and control systems in dynamic manufacturing organisations', Internal Report, MSI Research Institute, Loughborough University, UK.

Masood, T., Rahimifard, A. and Weston, R.H. (2007) 'A computer executable modelling approach to engineering production planning and control systems in dynamic manufacturing organisations', Paper presented in the Proceedings of the ICRM'07: International Conference on Responsive Manufacturing, September 17-19, Nottingham, UK.

Monden, Y. (1993) Toyota Production System: An Integrated Approach to Just-In-Time (2nd ed.). Norcross, GA: Industrial Engineering and Management Press.

Monfared, R.P. (2000) 'A component-based approach to design and construction of change capable manufacturing cell control systems', PhD Thesis, MSI Research Institute, Loughborough, UK, Loughborough University.

Monfared, R.P., West, A.A., Vera, D.A. and Conway, P.P. (2008) 'Evaluating a new flexible soldering system for electronics small and medium enterprises', Paper presented in the Proceedings of the IMechE, Part B: Journal of Engineering Manufacture, Vol. 222, pp.273-283.

Norrie, M.C. (1995) 'Integration approaches for CIM', Paper presented in the Proceedings of the International Conference on Management of Data, San Jose, California, United States.

Ohno, T. (1988) Toyota Production System. Cambridge, MA: Productivity Press.

Petrie, C.J. (1992) Introduction in Enterprise Integration Modelling, in C.J. Petrie (Ed.). Cambridge, MA: MIT Press.

Rahimifard, A. and Weston, R.H. (2007) 'The enhanced use of enterprise and simulation modelling techniques to support factory changeability', Int. J. Computer Integrated Manufacturing, Vol. 20, pp.307-328.

Robinson, S. (1997) 'Simulation model verification and validation: increasing the users' confidence', Paper presented in the Proceedings of the 1997 Winter Simulation Conference, $53-59$.

Sargent, R.G. (2005) 'Verification and validation of simulation models', Paper presented in the Proceedings of the 2005 Winter Simulation Conference, pp.130-143.

Spearman, M.L., Woodruff, D.L. and Hopp, W.J. (1990) 'CONWIP: a pull alternative to kanban', Int. J. Production Research, Vol. 18, No. 2, pp.245-257.

Stevenson, M., Hendry, L.C. and Kingsman, B.G. (2005) 'A review of production planning and control: the applicability of key concepts to the make-to-order industry', Int. J. Production Research, Vol. 43. pp.869-898. 
Szegheo, O. (2000) 'Introduction to enterprise modelling', in A. Rolstadas and B. Andersen (Eds), Enterprise Modeling: Improving Global Industrial Competitiveness. Norwell, MA, USA: Kluwer Academic Publishers, pp.21-32, ISBN: 0-7923-7874-1.

Tabe, T., Murumatsu, R. and Tanaka, Y. (1980) 'Analysis of production ordering quantities and inventory variations in a multi-stage production ordering system', Int. J. Production Research, Vol. 18, No. 2, pp.245-257.

Vernadat, F.B. (1996) Enterprise Modelling and Integration: Principles and Applications. London, UK: Chapman \& Hall.

Vernadat, F.B. (2002) 'Enterprise modelling and integration (EMI): current status and research perspectives', Annual Reviews in Control, Vol. 26. pp.15-25.

Weston, R.H., Zhen, M., Ajaefobi, J.O., Rahimifard, A., Guerrero, A., Masood, T., Wahid, B. and Ding, C. (2007) 'Simulating dynamic behaviours in manufacturing organisations', Paper presented in the Proceedings of the IESM'07: International Conference on Industrial Engineering and Systems Management, May 30-June 2, Beijing, China.

Weston, R.H., Zhen, M., Rahimifard, A., Ajaefobi, J.O., Ding, C., Guerrero, A., Wahid, B. and Masood, T. (2006) 'Simulation model interoperability in support of complex organisation design and change', Paper presented in the Proceedings of the ESM'06: 20th European Simulation and Modelling Conference, October 23-25, Toulouse, France.

Zapfel, G. (1996) 'Production planning in the case of uncertain individual demand extension for an MRPII concept', Int. J. Production Economics, Vol. 46-47, pp.153-164. 